\title{
AN IMPROVED METHOD FOR SIMULTANEOUS DETERMINA- TION OF EXCHANGEABLE BODY SODIUM AND POTASSIUM
}

\author{
By C. V. ROBINSON, WALTER L. ARONS, AND A. K. SOLOMON \\ (From the Biophysical Laboratory and the Department of Medicine of the Harvard Medical \\ School, the Medical Service of the Peter Bent Brigham Hospital, and the Physics \\ Department of the New England Center Hospital)
}

(Submitted for publication July 28, 1954; accepted September 8, 1954)

In a previous paper (1) a method was reported for the simultaneous determination of exchangeable body sodium and potassium by the isotope dilution technique in which the two isotopes are separated by ion exchange chromatography. ${ }^{1}$ The method presented here uses a differential counting technique ${ }^{2}$ to measure the amounts of each isotope without separation, thus effecting a considerable simplification.

Potassium 42 has considerably harder $\beta$-rays than does sodium 24, whereas sodium 24 emits many more $\gamma$-rays. ${ }^{3}$ In consequence a suitable pair of detectors for the differential counting of these isotopes is a G. M. dip counter for $\beta$-ray detection and a well-type scintillation counter for $\gamma$-ray detection. With the particular technique employed, the counting rates for serum samples labelled with $\mathrm{Na}^{24}$ are approximately 1.8 times greater in the scintillation than in the dip counter, whereas serum labelled with $\mathrm{K}^{\mathbf{4 2}}$ counts approximately 10 times more in the dip than in the scintillation counter. The accurately determined values of these two ratios can be used to calculate the separate activities in any mixed sample from its observed counting rates in the two detectors making it possible to determine exchangeable body

1 A discussion of the general principles underlying the application of the isotope dilution technique to the measurement of body constituents may be found in the paper by Edelman and his co-workers (2). The physiologic implications and clinical applications of body electrolyte measurements are discussed by Corsa and his co-workers (3), Arons, Vanderlinde, and Solomon (1) and Forbes and Perley (4).

2 Two other types of differential counting of $K^{* 3}$ and $\mathrm{Na}^{\mu}$ are reported by Tait and Williams (5) and by Burrows, Hine, and Ross (6).

\begin{tabular}{|c|c|c|c|c|c|}
\hline$(7)$ & $\mathrm{Na}^{24}$ & $\begin{array}{c}\text { Half life } \\
15.04 \text { hours }\end{array}$ & $\begin{array}{c}\text { P-rays } \\
1.4 \mathrm{Mev}\end{array}$ & $\begin{array}{c}r \text {-rays } \\
2.8 \text { and } 1.4 \mathrm{Mev}\end{array}$ & $\begin{array}{c}\% \\
100\end{array}$ \\
\hline & $K^{2}$ & 12.44 hours & $\begin{array}{l}3.6 \mathrm{Mev} \\
2.1 \mathrm{Mev}\end{array}$ & $\begin{array}{l}\text { none } \\
1.5 \mathrm{Mev}\end{array}$ & \\
\hline
\end{tabular}

sodium and potassium simultaneously without any separation of the ions from one another.

The accuracy and practicability of the method were tested in vitro by comparison of the assays of mixtures by differential counting with the known values; and in vivo by comparison of the values of exchangeable body sodium and potassium obtained simultaneously by this method on seven normal subjects with separate values obtained on the same subjects. The results compare favorably with those obtained by more complex techniques.

\section{THE EQUATIONS FOR DIFFERENTIAL COUNTING}

To express the relationships which exist among the various counting rates, the following symbols are used:

$\mathrm{S}_{\mathrm{na}}=$ the scintillation counting rate of the $\mathrm{Na}^{2}$,

$S_{k}=$ the scintillation counting rate of the $K^{2}$,

$S_{t}=$ the total scintillation counting rate of the mixture,

$D_{n a}, D_{k}$ and $D_{t}$ are the corresponding quantities for the dip counter,

$r_{n a}=D_{n a} / S_{n a}$, the ratio of sodium counts in the two detectors, and

$r_{k}=S_{k} / D_{k}$, the ratio of potassium counts in the two detectors.

Now, by definition:

(1) $\mathrm{S}_{\mathrm{t}}=\mathrm{S}_{\mathrm{ma}}+\mathrm{S}_{\mathrm{k}}$

and

(2) $D_{t}=D_{k}+D_{n a}$.

Since the values $S_{n a}$ and $D_{k}$ are the calculated individual counting rates used to determine the respective body masses, the quantities $S_{\mathbf{k}}$ and $D_{\text {man }}$ which are not required for the calculations are eliminated to obtain:

(3) $S_{t}=S_{n a}+r_{k} D_{k}$

and

(4) $D_{t}=D_{k}+r_{m a} S_{n a}$,

and solving these, we have:

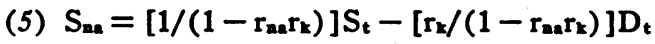
and

(6) $D_{k}=\left[1 /\left(1-r_{n a k}\right)\right] D_{t}-\left[r_{n a} /\left(1-r_{m a} r_{k}\right)\right] S_{t}$.

After the ratios have been accurately measured, their values are substituted in the brackets to give numerical 
coefficients. In most of the present work, for example, the values are $r_{m a}=0.541$ and $r_{x}=0.0986$, giving rise to the final equations: and

(7) $\mathrm{S}_{\mathrm{ma}}=1.056 \mathrm{~S}_{\mathrm{t}}-0.1043 \mathrm{D}_{\mathrm{t}}$

(8) $\mathrm{D}_{\mathrm{k}}=1.056 \mathrm{D}_{\mathrm{t}}-0.571 \mathrm{~S}_{\mathrm{t}}$

The values $S_{m a}$ and $D_{k}$ can be calculated readily for any mixed sample by substitution of the two observed counting rates, $S_{t}$ and $D_{t}$. These equations apply only to the pair of detectors given in this example. Any change of either detector, such as replacement of the dip tube, requires the determination of new values of the ratios to give new equations similar to 7 and 8 .

The equations are strictly correct only if the counts are made simultaneously with both detectors since the half-lives of the two isotopes are different so that it is impossible to apply exact decay corrections to the observed counting rates of the mixture. If the counting is arranged, however, so that no more than ten minutes elapses between the mid-times of determination of $S_{t}$ and $D_{t}$, no significant error is introduced by correcting the scintillation count with a $\mathrm{Na}^{2}$ decay factor to the dip counting time to give the values of $S_{n a}$ and $D_{k}$ at that time.

The derived scintillation rate $S_{m a}$ is used together with the injected sodium counts as measured with the scintillation counter in the calculation of the exchangeable body sodium and similarly the derived dip counting rate $D_{k}$ is used together with the injected potassium counts as measured in the dip counter to calculate the exchangeable body potassium.

\section{EXPERIMENTAL METHOD}

Sodium 24 and potassium 42 were obtained from the Atomic Energy Commission at the Brookhaven National Laboratory and prepared as previously described (1). For the in vitro experiments standard solutions of $\mathrm{Na}^{2}$ and $\mathrm{K}^{*}$ in plasma were prepared to contain approximately equal activities as measured with the dip tube. These standard solutions were mixed in proportions of $1: 1,3: 1$, and $25: 3\left(\mathrm{~K}^{*}: \mathrm{Na}^{*}\right)$ to give a range of activity ratio beyond that expected in normal and abnormal body electrolyte conditions.

For the simultaneous sodium and potassium measurements in human subjects, the $\mathrm{Na}^{24}$ and $\mathrm{K}^{* 3}$ solutions were diluted in isotonic saline so that the $50 \mathrm{ml}$. injection volume administered in each case would contain $10 \mu \mathrm{c}$. of $\mathrm{Na}^{3}$ or $350 \mu$ c. of $\mathrm{K}^{4}$. These relative activities compensate for the different concentrations of sodium and potassium found in serum. For single measurements, $350 \mu \mathrm{c}$. of $\mathrm{K}^{\mathbf{2}}$ or $125 \mu \mathrm{c}$. of $\mathrm{Na}^{*}$ were injected. These solutions were neutralized, sterilized, and injected serially via the tubing of a 5 per cent dextrose-in-water intravenous infusion. All radioactivity injections were of $50 \mathrm{ml}$. volume from calibrated syringes to minimize the error of injection which was found to be about 0.3 per cent. Af-

\footnotetext{
4 See Footnote 3.
}

ter a 24-hour equilibration period during which all urine was collected, $50 \mathrm{ml}$. of blood were drawn and the serum separated by centrifugation. The amount of radioactivity lost in feces and sweat is insignificant in normal subjects (1).

To measure the injected radioactivity, duplicate standard solutions of $\mathrm{Na}^{*}$ (dilution 10:250) were counted in triplicate for 10,000 counts in the scintillation counter and $\mathrm{K}^{\omega}$ (dilution $1: 1000$ ) standards were similarly assayed in the dip counter. Serum samples for the in vivo measurements and the in vitro mixtures were counted in duplicate to 10,000 counts in both scintillation and dip counters. For single determinations of the exchangeable body sodium, measurements were made in the scintillation counter; similarly for single potassium determinations the dip counter was used. Urine was counted in duplicate to 5000 counts in each detector. The usual corrections for decay, background and dead time were made.

The whole body radiation resulting from the injections of radioactivity in the combined experiment, as computed by the method of Marinelli, Quimby, and Hine (8), is 0.45 equivalent roentgens; the dose is appreciably less when only one isotope is used. Since this combined dose was used only once and the single dose twice in these experiments, the total body radiation administered was considered to be well within tolerance limits.

The sodium and potassium concentrations in each serum sample were determined in duplicate on each of two days on a Perkin-Elmer flame photometer utilizing an internal standard. The average values were used in the calculations of the exchangeable body sodium and potassium. These data, together with the corrected activity values were substituted in the isotope dilution formula ${ }^{5}$ to give the exchangeable body sodium and potassium.

\section{COUNTING EQUIPMENT}

\section{The dip counter}

The type of tube used in this work ${ }^{6}$ is the same as was employed previously when the isotopes were separated by ion-exchange chromatography. A section of the dip counter, cup and supports is shown in Figure 1. The upper, fixed support holds the tube rigidly and receives the top of the brass cup. A hinged, lower support terminates in a conical point which engages the bottom of the cup. The two supports serve to position the cup in a positive

$$
\begin{aligned}
& 5 \text { Total exchangeable electrolyte }= \\
& \text { (activity injected - activity excreted) }
\end{aligned}
$$

(activity in body fluid sample/electrolyte in sample)

- Described in reference (9) and manufactured by Radiation Counter Laboratories as Mark I, Model 80A. The tube is $105 \mathrm{~mm}$. long by $18 \mathrm{~mm}$. in diameter with a sensitive region $36 \mathrm{~mm}$. long and a glass wall $30 \mathrm{mg} . /$ $\mathrm{cm}^{2}$. in thickness. This tube is somewhat photosensitive and the portions exposed to light should be coated with black paint. 


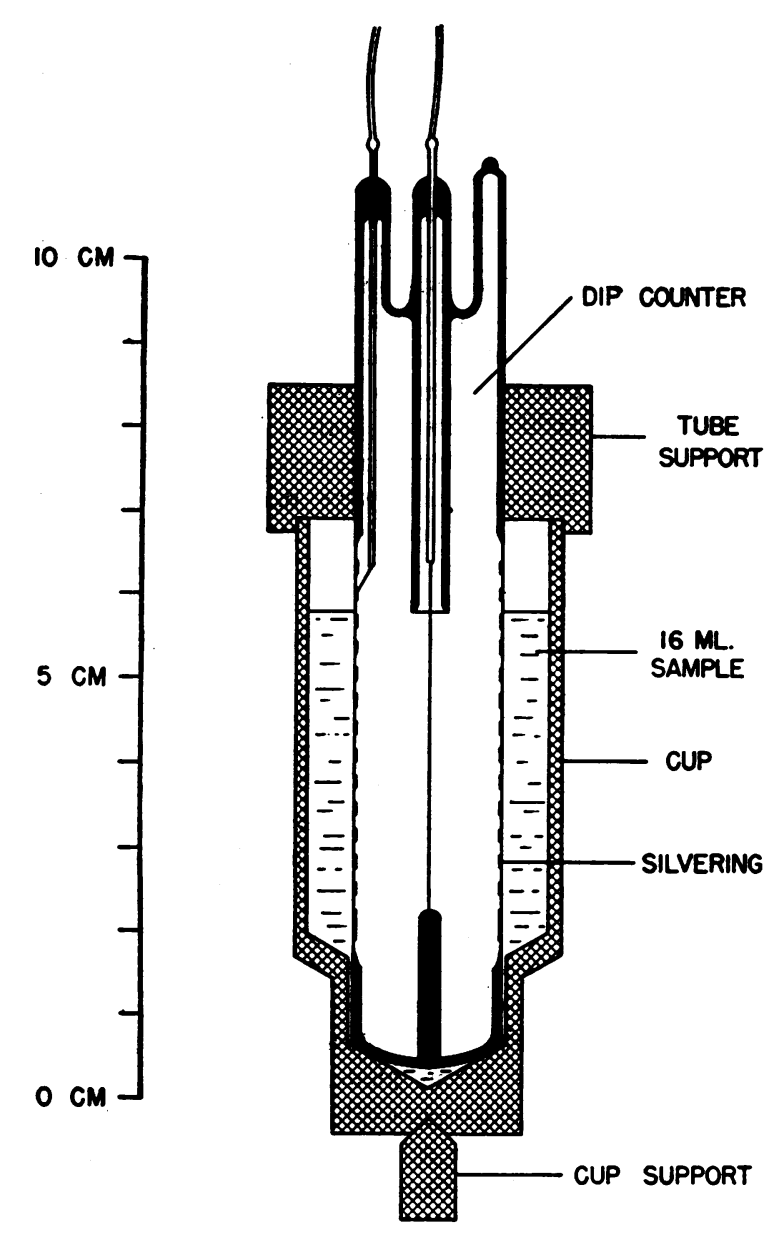

Fig. 1. A Section of the Dip Counter, Cup and SUPPORTS

and reproducible manner. This construction, together with the practice of using the same cup for all measurements, insures a constant geometry of solution. A larger diameter was chosen for the present cup in order to favor the detection of $\mathrm{K}^{\text {ss }}$ over $\mathrm{Na}^{\text {* }}$ even though a larger serum sample, $16 \mathrm{ml}$., is required. This amount need not be pipetted to better than $\pm 0.1 \mathrm{ml}$. since it exceeds the

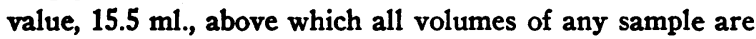
found to give nearly the same counting rate.

In order to check the reproducibility of dip counting, measurements were made on a set of twelve identical serum samples labelled with $\mathrm{K}^{\mathrm{s}}$. The total count on each sample was about 12,000 and the coefficient of variation was found to be 1.03 per cent which compares favorably with the 0.91 per cent expected from the counting statistics.

The normal background of the counter with the cup filled and in position but without further shielding is 10 to $16 \mathrm{c} / \mathrm{m}$. During a series of measurements the cup and counter are washed and wiped between each sample but, nevertheless, a gradual increase in background to as much as 100 per cent due to contamination may be observed. The background value, however, may be determined at intervals to sufficient accuracy so that the error of its determination does not contribute significantly to the calculated net counts of any of the samples or standards which are measured.

\section{The scintillation counter}

This apparatus consists of a commercial, well-type, scintillation unit ${ }^{7}$ surrounded by 3 inches of lead shielding. The crystal is of a standard type, ${ }^{8} 1$ and $3 / 4$ inches in diameter, 2 inches high and containing a well $3 / 4$ inch in diameter and 1 and $1 / 2$ inches deep. The well accommodates a sample of $2 \mathrm{ml}$. volume contained in a standard 13 by $100 \mathrm{~mm}$. test tube ${ }^{\theta}$ and is lined by a $1 / 16$ inch thickness of steel to insure absorption of the $\beta$-particles.

The scintillation counter is especially convenient compared to the dip counter, since no decontamination is required between samples. The background has a relatively steady value but is high enough $(104 \mathrm{c} / \mathrm{m}$ in our present apparatus) so that the statistical error in its determination contributes significantly to the error of the net count. Account is taken of this in the calculations of the errors shown in Tables I and II.

The $2 \mathrm{ml}$. volume needs to be pipetted accurately as the counting rate is directly proportional to the activity in the test tube. Ten identical samples of serum labelled with $\mathrm{Na}^{24}$, each counted to 11,500 counts, gave a coeffcient of variation of 1.12 per cent with 0.93 per cent expected from the counting statistics.

TABLE I

A comparison of known and simultaneously determined activities of in vitro mixtures

\begin{tabular}{ccccc}
\hline \hline $\begin{array}{c}\text { Mixture } \\
\text { ratio } \\
\mathrm{K}^{\text {1a/Nax }}\end{array}$ & $\begin{array}{c}\text { Counter } \\
\text { and } \\
\text { isotope* }\end{array}$ & $\begin{array}{c}\text { Activity } \\
\text { known from } \\
\text { separate } \\
\text { countingt } \\
\text { counts per } \\
\text { minule }\end{array}$ & $\begin{array}{c}\text { Activity } \\
\text { determined } \\
\text { by differential } \\
\text { counting } \\
\text { counts per } \\
\text { minute }\end{array}$ & Diff. \\
\hline 1 to 1 & $\mathrm{~S}_{\mathrm{na}}$ & $2712 \pm 13 \ddagger$ & $2720 \pm 18$ & +08 \\
& $\mathrm{D}_{\mathbf{k}}$ & $1750 \pm 10$ & $1727 \pm 28$ & -23 \\
3 to 1 & $\mathrm{~S}_{\mathrm{na}}$ & $1356 \pm 7$ & $1341 \pm 11$ & -15 \\
& $\mathrm{D}_{\mathbf{k}}$ & $2625 \pm 15$ & $2657 \pm 25$ & +32 \\
25 to 3 & $\mathrm{~S}_{\mathrm{ns}}$ & $\mathbf{5 8 2 \pm 3}$ & $584 \pm 9$ & +02 \\
& $\mathrm{D}_{\mathbf{k}}$ & $3126 \pm 18$ & $3138 \pm 25$ & +12 \\
\hline
\end{tabular}

* $S_{\mathrm{ma}}$ denotes the scintillation sodium count and $D_{k}$ denotes the G. M. dip potassium count.

$t$ These counts are calculated from the mixture ratios and from the measured activities of the original $K^{12}$ and $\mathrm{Na}^{24}$-labelled plasma standards for which $\mathrm{D}_{\mathrm{k}}=3501 \pm 20$ $\mathrm{c} / \mathrm{m}$ and $S_{\mathrm{na}}=5425 \pm 26 \mathrm{c} / \mathrm{m}$, respectively.

† The errors shown are the standard deviations expected from the counting statistics in counts per minute.

7 N. Wood Laboratories, SC-2L.

8 Thallium activated sodium iodide manufactured by The Harshaw Chemical Co.

${ }^{\bullet}$ Rimless culture tube Corning No. 9820. 
TABLE II

Two examples showing observed and derived counting rates together with their standard deviations due to counting statistics for cases (a) normal and (b) abnormal

\begin{tabular}{|c|c|c|c|c|c|c|c|c|}
\hline & \multicolumn{4}{|c|}{ A. Normal* } & \multicolumn{4}{|c|}{ B. Abnormal* } \\
\hline & Dip & S.D. & Scin. & S.D. & Dip & S.D. & Scin. & S.D. \\
\hline $\begin{array}{l}\text { Total counts (Approx.) } \\
\text { Time (Approx.) } \\
\text { Total observed rate, } c / m \dagger \\
\text { Background, } c / m \\
\text { Net observed rates } D_{t} \text { and } S_{t}, c / m\end{array}$ & $\begin{array}{r}20,000 \\
50 \mathrm{~m} \\
393 \\
15 \\
378\end{array}$ & $\begin{array}{l}0.7 \\
0.7 \\
4.7 \\
0.8\end{array}$ & $\begin{array}{r}22,000 \\
56 \mathrm{~m} \\
406 \\
149 \\
257\end{array}$ & $\begin{array}{l}0.7 \\
0.7 \\
1.0 \\
1.2\end{array}$ & $\begin{array}{r}21,000 \\
30 \mathrm{~m} \\
724 \\
17 \\
707\end{array}$ & $\begin{array}{l}0.7 \\
0.7 \\
2.4 \\
0.7\end{array}$ & $\begin{array}{r}20,000 \\
50 \mathrm{~m} \\
402 \\
110 \ddagger \\
292\end{array}$ & $\begin{array}{l}0.7 \\
0.7 \\
0.9 \\
1.0\end{array}$ \\
\hline Derived rates $D_{k}$ and $S_{\text {na, }} c / m$ & 253 & 1.4 & 232 & 1.5 & 580 & 0.9 & 235 & 1.4 \\
\hline
\end{tabular}

* Case $\mathrm{A}$ is J. V. of Table III with values $\mathrm{Na}_{0}=3,179 \mathrm{mEq}$. and $\mathrm{K}_{0}=4,035 \mathrm{mEq}$. with $\mathrm{Na}_{0} / \mathrm{K}_{0}$ ratio 0.79 . The range of ratios for the seven normal subjects of Table III is 0.74 to 0.94 . Case $\mathrm{B}$ has values $\mathrm{Na}_{0}=3,955 \mathrm{mEa}$. and $K_{0}=2,305 \mathrm{mEq}$. with an abnormal ratio of 1.72 .

t Counts per minute.

$\ddagger$ The improvement in this background is due to additional shielding.

\section{SOURCES OF ERROR}

\section{Errors due to counting statistics}

In evaluating any differential counting technique, one important consideration is the cumulative effect of the errors of measurement on the derived quantities; in this instance, the effect on $S_{m a}$ and $D_{k}$ of the errors in determining $r_{n a}, r_{k}, S_{t}$, and $D_{t}$.

The errors introduced by the uncertainty of the values of $r_{m a}$ and $r_{x}$ should be rendered insignificant by making sufficiently long counts on standard solutions so that their values are known to better than $1 / 2$ per cent. In our work, this is done whenever a new detector is put into service. In addition the ratios are given a rough check each time body mass measurements are made, by counting each of the injection standards in both counters. If each detector is provided with a long-lived standard, such as a tube of uranium salt with reproducible geometry, a further check on the constancy of the detectors may be made by counting these standards with each set of determinations.

TABLE III

A comparison of simultaneous measurements of exchangeable body sodium and potassium with single determinations in normal male subjects

\begin{tabular}{|c|c|c|c|c|c|c|}
\hline Subject & Age & Weight & $\begin{array}{c}\text { Exchange- } \\
\text { able } \\
\text { body } \mathrm{Na}\end{array}$ & $\begin{array}{c}\text { Difference } \\
\text { from mean } \\
\text { as \% of } \\
\text { mean }\end{array}$ & $\begin{array}{c}\text { Exchange- } \\
\text { able* } \\
\text { body K }\end{array}$ & $\begin{array}{l}\text { Difference } \\
\text { from mean } \\
\text { as \% of } \\
\text { mean }\end{array}$ \\
\hline B. B. & $\begin{array}{c}\text { (yrs.) } \\
28\end{array}$ & $\begin{array}{l}\left(K_{g}\right) \\
92.0\end{array}$ & $\begin{array}{l}(m E q .) \\
3,243 \\
3,129\end{array}$ & +1.8 & $\begin{array}{l}(m E q .) \\
4,084 \\
3,910\end{array}$ & +2.2 \\
\hline K. O'D. & 19 & 89.1 & $\begin{array}{l}3,648 \\
3,421\end{array}$ & +3.2 & $\begin{array}{l}4,266 \\
4,440\end{array}$ & -2.0 \\
\hline A. $\mathbf{R}$. & 30 & 83.8 & $\begin{array}{l}3,158 \\
3,157\end{array}$ & 0.0 & $\begin{array}{l}4,053 \\
3,714\end{array}$ & +4.4 \\
\hline J. H. & 26 & 90.0 & $\begin{array}{l}3,379 \\
3,132\end{array}$ & +3.8 & $\begin{array}{l}4,243 \\
4,260\end{array}$ & -0.2 \\
\hline E. P. & 26 & 62.3 & $\begin{array}{l}2,730 \\
2,648\end{array}$ & +1.5 & $\begin{array}{l}2,984 \\
2,814\end{array}$ & +2.9 \\
\hline J. V. & 30 & 85.0 & $\begin{array}{l}3,088 \\
3,179\end{array}$ & -1.5 & $\begin{array}{l}3,862 \\
4,035\end{array}$ & -2.2 \\
\hline J. W. & 29 & 80.0 & $\begin{array}{l}3,036 \\
3,133\end{array}$ & -1.6 & $\begin{array}{l}3,855 \\
3,684\end{array}$ & +2.3 \\
\hline \multicolumn{4}{|c|}{ Coefficient of variation } & $3.2 \%$ & & $3.6 \%$ \\
\hline
\end{tabular}

* Results of the single measurements are listed first and the simultaneously determined values second. The two single and the simultaneous measurements were carried out in most instances at seven-day intervals on three successive weeks. 
Application of the rules for the accumulation of errors to equations 5 and 6 gives expressions for the errors in $D_{\mathbf{k}}$ and $S_{\mathrm{an}}$. The terms containing $r_{\mathbf{k}}{ }^{3}$ and those containing the squares of the errors of $r_{x}$ and $r_{m a}$ may be neglected, if one assumes the degree of accuracy discussed above. The simplified expressions are: and$$
\text { (9) } d\left(S_{n z}\right)=\left[1 /\left(1-r_{k} r_{n a}\right)\right] \times d\left(S_{t}\right)
$$

$$
\begin{array}{r}
d\left(D_{k}\right)=\left[1 /\left(1-r_{\mathbf{k}} r_{n a}\right)\right] \times \\
\quad\left[r_{m a}^{2} \times d^{2}\left(S_{t}\right)+d^{2}\left(D_{t}\right)\right]^{1 / 2},
\end{array}
$$

where the symbol $d(X)$ designates the standard deviation of $\mathrm{X}$ in counts per minute. For the values $r_{x}=0.10$ and $r_{\mathrm{na}}=0.54$, the equations become:

and

(11) $\mathrm{d}\left(\mathrm{S}_{\mathrm{ns}}\right)=1.06 \mathrm{~d}\left(\mathrm{~S}_{\mathrm{t}}\right)$

(12) $d\left(D_{k}\right)=1.06 \times\left[0.29 d^{2}\left(S_{t}\right)+d^{2}\left(D_{t}\right)\right]^{1 / 2}$.

In order to illustrate the accumulation of errors in solving the equations, two cases have been chosen, one a normal subject and the other a patient exhibiting an unusually high body $\mathrm{Na} / \mathrm{K}$ ratio (see Table II). Approximately the same doses of $350 \mu \mathrm{c}$. of $\mathrm{K}^{\mathrm{s}}$ and $10 \mu \mathrm{c}$. of $\mathrm{Na}^{24}$ were given to each subject. The counts have been corrected to a single time in each case and the derived rates and their errors calculated from equations 11 and 12.

The results show that the errors in the derived quantities, $S_{\mathrm{na}}$ and $\mathrm{D}_{\mathbf{k}}$, are approximately 1.4 per cent which is twice the 0.7 per cent of the observed counts. This increase depends not only on the accumulation of errors in solving the equations but also on a significant contribution from the uncertainty in the value of the background of the scintillation counter. The background of the dip counter is low enough not to contribute significantly. The counting errors are found to be no greater for the abnormal than for the normal subject.

The urine samples are generally counted in duplicate to 5,000 counts in each detector. Because of the preponderance of potassium activity, the sodium determination may have a rather large percentage error. Since the excreted activity represents only about 5 per cent of the injected activity for each isotope, the inaccuracies thus introduced into the final body electrolyte values are negligible.

The injection standards are counted to $1 / 2$ per cent accuracy. When this error is included about 0.1 per cent is added to each of the errors shown for the derived quantities. Thus the maximum overall counting error found in these examples is 1.6 per cent, with 1.4 per cent as an average value.

\section{The effect of specific gravity}

The specific gravity of the sample affects the counting rate of the dip counter, but not of the scintillation counter. Account must be taken of this effect in determining the exchangeable body potassium, since an aqueous, rather than a serum, dilution of the injected material is used. The dip count obtained from this standard must be decreased by a small amount to give the serum-equivalent figure for use with the $D_{k}$ value in the calculation of exchangeable body potassium. In the corresponding sodium calculation the scintillation count on the aqueous standard is used as serum-equivalent without correction.

The magnitude of the specific gravity correction factor, as determined from measurements by us on serum and sucrose solutions, is $1+0.7(\eta-1)$ for $\mathrm{K}^{23}$ in a medium of specific gravity $\eta$. For example, with the average serum value $\eta=1.025$ the $\mathrm{K}^{22}$ dip counting rate is 1.8 per cent lower than it would be in aqueous solution. The effect on $\mathrm{Na}^{3}$ is approximately the same.

Although the ratios $r_{n a}$ and $r_{k}$ are affected by variations in specific gravity, the values determined for serum of average specific gravity are satisfactory for the activity calculations in all but exceptional cases. A deviation of specific gravity downward 1 per cent from normal will cause the equations to give values of $S_{n a}$ which are approximately 0.1 per cent too low and values of $D_{k}$ which are approximately 0.3 per cent too high. Equal and opposite errors in these quantities are caused by a specific gravity 1 per cent higher than normal. Since a 1 per cent deviation is unusual and since the errors introduced are small compared to other errors in the measurements, it is not likely that a case will be encountered for which it would be worthwhile to recalculate the values of $r_{n a}$ and $r_{\mathbf{x}}$ and set up new equations.

\section{Summary of expected errors in determining exchangeable body sodium and potassium}

From an analysis of the pairs of flame photometer values measured for each electrolyte, the average values, used in the final calculations, are estimated to have standard deviations of 0.5 per cent for sodium and 1.0 per cent for potassium.

The contributions of the following effects are estimated to be negligible for normal subjects: errors in urine values, errors in dilutions of the standards, and errors due to variations of the specific gravity of the serum.

In summary, the expected errors for normal subjects for sodium and potassium respectively are: injection, 0.3 per cent each; differential counting of serum (case A, Table II), 1.5 per cent and 1.4 per cent; counting of standards, 0.5 per cent each; and flame photometer, 0.5 per cent and 1.0 per cent. The accumulated effects of these errors on the values of the exchangeable body sodium and potassium are 1.7 per cent and 1.8 per cent. respectively.

\section{RESULTS AND DISCUSSION}

In order to establish the basic validity of the present differential counting technique for measuring the separate activities of sodium 24 and potassium 42 in mixtures of these isotopes, an in vitro trial of the method was first made. In these experiments known activities of $\mathrm{Na}^{24}$ and $\mathrm{K}^{42}$ in 
three different mixtures $\left(1: 1,3: 1,25: 3 \mathrm{~K}^{42} /\right.$ $\mathrm{Na}^{24}$ ) of these isotopes were compared with the values derived by use of equations 5 and 6 . This comparison is presented in Table I from which it is apparent that the derived activities fall well within the limits of the counting errors of the corresponding known activities.

After satisfactory accuracy had been demonstrated in vitro, an in vivo study was undertaken. Separate determinations and a simultaneous determination of exchangeable body sodium and potassium were made on each of seven normal, adult males at one week intervals. The subjects were assumed to be in electrolyte balance during the experimental period. A comparison of the single measurements with their counterparts in the combined determinations is shown in Table III and demonstrates a satisfactory degree of reproducibility. No systematic error is evident in the signs of the differences. The coefficients of variation of the exchangeable body sodium and potassium measurements estimated from these seven cases are 3.2 per cent and 3.6 per cent, respectively. Thus differences of 9.0 per cent and 10.0 per cent, respectively, must exist between successive body sodium and potassium measurements to indicate a significant difference in these values by the criterion previously used (1)..$^{10}$

The coefficients of variation of the present method are somewhat higher than those obtained from similar measurements on a set of six subjects by the ion-exchange chromatographic method (1), 2.6 per cent for sodium and 2.0 per cent for potassium. The sodium values of 3.2 per cent for the present method and 2.6 per cent for the previous method are in good agreement. ${ }^{11}$ The potassium values, 3.6 per cent and 2.0 per cent differ appreciably but they are not found to be significantly different on a 5 per cent probability basis. The discrepancy between the estimated total errors of the technique, 1.7 per cent for sodium and 1.8 per cent for potassium, and the coefficients of variation found from the in vivo data, 3.2 and 3.6 per cent, respectively, indicate the presence of

10 Significance on a 2 S.D. or 4.6 per cent level of probability. The difference must exceed $2.83 \times \mathrm{C}$. of $\mathrm{V}$. for single determinations.

11 Relative to the degrees of approximation in the estimates of the coefficients of variation based on six or seven cases. other sources of variation, probably both technical and biological, which were not taken into account.

In addition to the simultaneous body sodium and potassium measurements in normal subjects, similar determinations have also been carried out on more than thirty patients with various metabolic abnormalities. The introduction of a differential counting technique has considerably simplified and facilitated simultaneous measurements of body electrolytes as compared with the procedures previously described $(1,10)$.

\section{SUMMARY}

An improved method for the simultaneous determination of exchangeable body sodium and potassium, utilizing a differential counting technique is described. This technique makes it possible to measure the individual radioactivities of $\mathrm{Na}^{24}$ and $\mathrm{K}^{42}$ in solutions containing these isotopes without first separating them, as was heretofore necessary. The accuracy of the measurement of exchangeable body sodium and potassium by this method has been demonstrated by the satisfactory agreement obtained between single and simultaneously determined values on each of seven normal, male subjects.

The present procedure has been found to be considerably less complex and time-consuming than those previously used.

\section{ACKNOWLEDGMENTS}

This work was supported in part by the Atomic Energy Commission and in part by the Medical Research and Development Board, Office of the Surgeon General, Department of the Army, under Contract No. DA-49007-MD-135.

\section{REFERENCES}

1. Arons, W. L., Vanderlinde, R. J., and Solomon, A. K., II. The simultaneous measurement of exchangeable body sodium and potassium utilizing ion exchange chromatography. J. Clin. Invest., 1954, 33, 1001.

2. Edelman, I. S., Olney, J. M., James, A. H., Brooks, L., and Moore, F. D., Body composition: studies in the human being by the dilution principle, Science, 1952, 115, 447.

3. Corsa, L., Jr., Olney, J. M., Jr., Steenberg, R. W., Ball, M. R., and Moore, F. D., The measurement of exchangeable potassium in man by isotope dilution. J. Clin. Invest., 1950, 29, 1280. 
4. Forbes, G. B., and Perley, A., Estimation of total body sodium by isotopic dilution. I. Studies on young adults. J. Clin. Invest., 1951, 30, 558.

5. Tait, J. F., and Williams, E. S., Assay of mixed radioisotopes. Nucleonics, 1952, 10, No. 12, 47.

6. Burrows, B. A., Hine, G. J., and Ross, J. F., The simultaneous determination of radiosodium, radiopotassium, and radiosulfate spaces. Clin. Research Proc., 1954, 2, 81.

7. Hollander, J. M., Perlman, I., and Seaborg, G. T., Table of isotopes. Revs. of Mod. Phys., 1953, 25, 469.
8. Marinelli, L. D., Quimby, E. H., and Hine, G. J., Dosage determination with radioactive isotopes. II. Practical considerations in therapy and protection. Am. J. Roentgenol., 1948, 59, 260.

9. Solomon, A. K., and Estes, H. D., The measurement of radioactivity in solution. Rev. Scient. Instruments, 1948, 19, 47.

10. James, A. H., Brooks, L., Edelman, I. S., Olney, J. M., and Moore, F. D., Body sodium and potassium. I. The simultaneous measurement of exchangeable sodium and potassium in man by isotope dilution. Metabolism, 1954, 3, 313. 